\title{
WORKABILITY STUDY FOR RECYCLED AGGREGATES
}

\author{
Parekh D. N. ${ }^{1}$ and Modhera C D. ${ }^{2}$ \\ ${ }^{1}$ Research Scholar, Applied Mechanics Department; SVNIT; \\ ${ }^{2}$ Professor; Applied Mechanics Department; SVNIT; Surat
}

\begin{abstract}
:
Significant quantities of waste are being produced and discarded by the construction and demolition $(C \& D)$ industries within the Asia and many other developed countries, and this is likely to increase considerably in the future. On the other hand, in recent years the construction industry throughout the world has supported initiatives to improve sustainability by increasing the use of recycled aggregates in concrete production. This is mainly because of the depletion of quality primary aggregates and in some quarters, greater awareness of environmental protection.

A laboratory experimental programme aimed at examining the performance of recycled aggregates, produced with known source of concrete and unknown source of concrete. Known source of concrete were prepared by a popular concrete mix 0.55:1:1.5:3, which was used here for preparation of known source of aggregate. Another source of aggregates was laboratory tested concrete specimens whose age or strength was not known. Recycled aggregates were prepared with help of laboratory type jaw crusher. All aggregates were tested as per IS recommendations and results compared with natural coarse aggregate (NCA) and IS requirements. All these properties of aggregates and their effect on concrete are reported in this paper. Water absorption and specific gravity are very important property for RCA. Hence water absorption was checked for different time intervals. All mechanical properties of NCA and RCA were determined and compared with IS requirements. At the fresh state, the slump loss and fresh density for various concrete mixes were determined.
\end{abstract}

Key Words: Recycled aggregates (RA), Recycled coarse aggregate (RCA), Recycled aggregate concrete (RAC)

\section{PRELIMINARY REMARK}

Concrete is the premier construction material across the world and the most widely used in all types of civil engineering works, including infrastructure, low and high-rise buildings, defense installations, environment protection and local/domestic developments. Concrete is a manufactured product, essentially consisting of cement, aggregates, water and admixture(s). Among these, aggregates, i.e. inert granular materials such as sand, crushed stone or gravel form the major part. Traditionally aggregates have been readily available at economic prices and of qualities to suit all purposes. However, in recent years the wisdom of our continued wholesale extraction and use of aggregates from natural resources has been questioned at an international level. This is mainly because of the depletion of quality primary aggregates and greater awareness of environmental protection. In light of this, the availability of natural resources to future generations has also been realized.

\section{1) Introduction}

Significant quantities of waste are being produced and discarded by the construction and demolition $(C \& D)$ industries within the Asia and many other developed countries, and this is likely to increase considerably in the future. On the other hand, in recent years the construction industry throughout the world has supported initiatives to improve sustainability by increasing the use of recycled aggregates in concrete production. This is mainly because of the depletion of quality primary aggregates and in some quarters, greater awareness of environmental protection. Indeed, it is widely acknowledged in some quarters that recycling of construction \& demolition $(\mathrm{C} \& \mathrm{D})$ waste for use as aggregate in the production of new concrete is not only technically viable but under certain circumstances also represents an environmentally sustainable and economically practicable route to converting this material into a valuable resource.[1-4]. Several research projects have been carried out to assess the effects of recycled aggregates on fresh and some engineering properties of concrete. [1-3] During the last few years, various properties of recycled aggregates (RA) have been investigated with the aim of using them in concrete manufacture. This benefit includes a reduction of the amount of natural aggregates extracted from quarries and river-beds, which are used in concrete production and other applications as well.

These aggregates which are often used in the production of concrete are named as recycled aggregates, mainly obtained from crushed concrete

\section{2) Reasons for Use of Recycled Aggregate}

It is now widely accepted that there is a significant potential for reclaiming and recycling demolished debris for use in value added applications to maximize economic and environmental benefits. As a direct result of this, recycling industries in many part of the world, including South Africa, at present converts low-value waste into secondary construction materials such as a variety of aggregate grades, road materials and aggregate fines (dust) [5]. Often these materials are used in as road 
construction, backfill for retaining walls, low-grade concrete production, drainage and brickwork and block work for low-cost housing. With this background, the study reported here was undertaken to examine suitability of recycled coarse aggregates (RCA).

\section{EXPERIMENTAL PROGRAMME}

A popular concrete mix given below in table - I was used here for experiment purpose.

Table I

Mix Proportions

\begin{tabular}{|l|l|l|l|l|l|}
\hline \multirow{2}{*}{ Mix } & \multirow{2}{*}{ W } & \multirow{2}{*}{$\mathrm{C}$} & \multirow{2}{*}{ FA } & \multicolumn{2}{|l|}{$\begin{array}{l}\text { Coarse } \\
\text { Aggregate }\end{array}$} \\
\cline { 4 - 6 } & & & & RA & NA \\
\hline A & 0.55 & 1 & 1.5 & 0 & 3 \\
\hline
\end{tabular}

Table II

Results of Cement

\begin{tabular}{|c|c|c|c|}
\hline No & Type of Test & Results & IS - Limits \\
\hline 1. & Type of Cement & OPC 53 Grade & - \\
\hline 2. & Fineness Test & $7 \%$ & $<10 \%$ \\
\hline 3. & Normal Consistency & $30 \%$ & - \\
\hline 4. & Soundness Test. & $5 \mathrm{~mm}$ & $<10 \mathrm{~mm}$ \\
\hline 5. & Initial Setting time & 95 Minutes & $>30 \min$ \\
\hline 6. & Final Setting time. & 210 Minutes & $<600 \mathrm{~min}$ \\
\hline \multirow{3}{*}{7.} & \multirow{3}{*}{ Compressive Strength Test } & 27.5 MPa (3 - Days) & $>27 \mathrm{MPa}$ \\
\hline & & $38.5 \mathrm{MPa}$ (7 - Days) & $>37 \mathrm{MPa}$ \\
\hline & & $55.1 \mathrm{MPa}$ (28 - Days) & $>53 \mathrm{MPa}$ \\
\hline
\end{tabular}

These mixes were tested and then crushed (at 28 days) to obtain RCA for next phase of recycled aggregate. These aggregates are used as known source aggregates i.e. RA from mix A. Another source of RCA was laboratory tested specimens of concrete, whose source aggregates or source concrete was not known. These aggregates are used as unknown source aggregates i.e. RU. RCA was prepared in laboratory by using laboratory type jaw crusher. Natural coarse aggregate (NCA) and natural fine aggregates (NFA) were used from local source.

All types of recycled aggregates were tested for all types of aggregate tests as per Indian standards and compared to find out effect of type of parent concrete.

\section{1) Cement Testing}

An OPC 53 grade conforming to IS 12269 - 1987 [6] was used throughout the study for preparation of mix A and mix B concrete production. The samples of the cement were taken in accordance with the requirements of standard IS: 3535-1986[7] and tested by using the relevant specification of IS 4031 - 1996[8-18]. All results were shown in Table II with their respective Indian Standard (IS) requirements for comparisons.

Table - III

Testing results of aggregates

\begin{tabular}{|l|c|c|c|c|}
\hline & NC & RA & RU & NFA \\
\hline Specific Gravity & 2.84 & 2.39 & 2.35 & 2.70 \\
\hline Apparent Sp. Gravity & 2.77 & 2.34 & 2.31 & 2.67 \\
\hline Water Absorption (\%) & 0.89 & 5.08 & 7.57 & 0.80 \\
\hline
\end{tabular}




\begin{tabular}{|l|c|c|c|c|}
\hline Bulk Density $\left(\mathrm{kg} / \mathrm{m}^{3}\right)$ & 149 & 131 & 1290 & 1480 \\
\hline Apparent Density $\left(\mathrm{kg} / \mathrm{m}^{3}\right)$ & 282 & 253 & 2510 & 2680 \\
\hline Flakiness Value $(\%)$ & 14.4 & 24.2 & 25.33 & - \\
\hline Elongation Value (\%) & 16.4 & 18.6 & 21.50 & - \\
\hline
\end{tabular}

\section{2) Aggregate Testing}

All aggregate samples were taken by properly mixing all aggregates. Samples were prepared in accordance with IS: 2430 1995[19]

Sieves are conforming IS: 460-1962 [20-21] was used. Sieve Analysis of aggregates was carried out in accordance with IS: 2386 (PART I) - 1997 [20]. All the sample weight for different aggregate was taken in accordance with the table - II of IS 2386 (Part I) - 1997 [20].

Sieve Analysis of aggregates was carried out as per the guidelines given by respective IS [8, 20-23] and detail grading chart is shown in Fig 1. Jaw crusher opening for size has been decided by considering the Fineness Modulus (FM) of NCA. Here, in this study, NCA and RCA were used with same FM to overcome aggregate size effect in concrete.

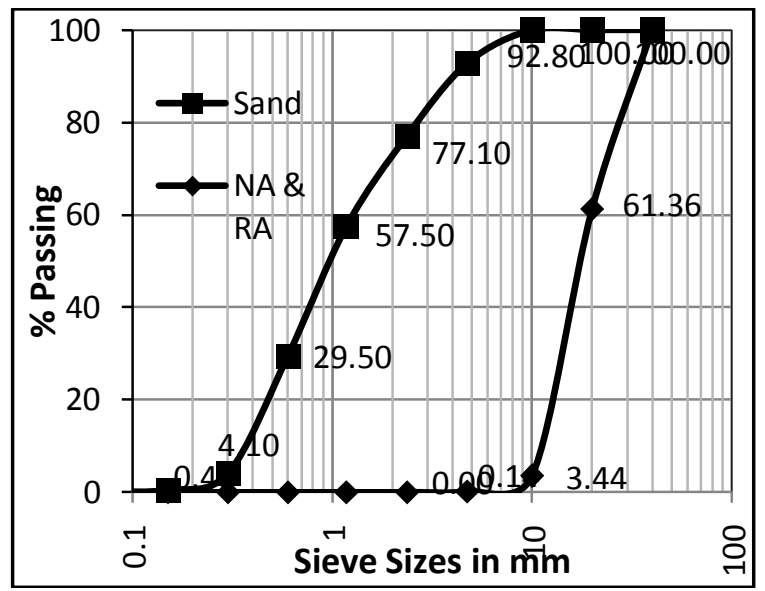

Fig. 1 Grading Curve of Fine and Coarse Aggregate

Elongation and flakiness index tests were carried out in accordance with IS: 2386 (PART I) - 1997[22], while specific gravity, apparent specific gravity, water absorption and bulk density were determined using IS: 2386 (PART III) - 1997[23]. Results were shown in Table III.

RCA was tested here without any type of treatment. But water absorption Vs logarithmic time scale graph is shown in fig 2.

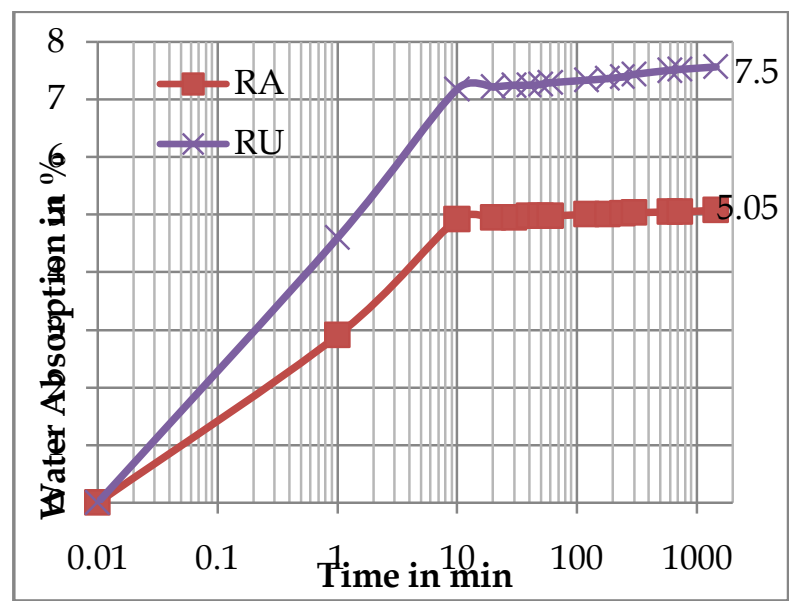

Fig. 2 water absorption vs logarithmic time 
Mechanical properties (impact value, crushing value and abrasion value) of aggregates were determined by using IS: 2386 (Part IV) - 1997[24] and shown in table IV below. It shows that all aggregates results were within prescribed IS limits.

Table IV

Mechanical properties of Aggregates

\begin{tabular}{|l|l|l|l|}
\hline & NCA & RA & RU \\
\hline Impact Value (\%) & 8.88 & 12.81 & 15.03 \\
\hline Crushing Value (\%) & 14.04 & 24.67 & 25.52 \\
\hline Abrasion Value (\%) & 15.58 & 25.94 & 26.70 \\
\hline IS Limit (Road) (\%) & 30.00 \\
\hline IS Limit (Buildings) (\%) & 45 (50 for abrasion) \\
\hline
\end{tabular}

\section{CONCRETE TESTING}

\section{1) FRESH PROPERTIES OF RAC}

Workability by slump cone was determined by using IS: 1199-1959[25] for RA concrete mixes. Concrete mixes were prepared with replacing the $\%$ of NCA by RCA. $10 \%, 20 \% 30 \%, 50 \%$ and $100 \%$ of NCA were replaced by RCA to check fresh properties of recycled aggregate concrete (RAC). Here mix A was prepared with same source of RCA and unknown source of RCA known here as AS and AU respectively. All results were shown below in fig 3.

One important point observed here that when recycled aggregate is used at high percentages (e.g., 50\% or higher), the concrete mixes were less cohesive (based on visual observations during mixing and casting) than those prepared with natural aggregates. The lack of cohesiveness of the concrete also affect the integrity and homogeneity of the fresh concrete during casting, which in turn would affect the mechanical and durability properties of the hardened concrete.

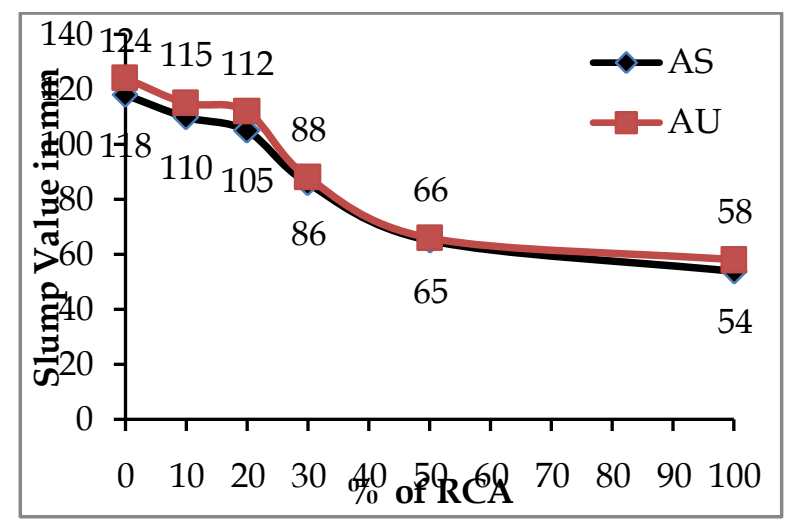

Fig 3 Workability of Mix A

\section{CONCLUSIONS:}

The conclusions of this study can be summarized as follows.

- Water absorption of RCA was 5 to 9 times higher and specific gravity of is $15 \%$ to $20 \%$ lower than the NCA. Furthermore, RCA had 9 to $11 \%$ lower density. Attached cement mortar and voids in that are the basic reason behind such behaviour.

- Water absorption was plotted with logarithmic time scale in fig 2. This shows that major water absorption for any recycled aggregate is occurred within first $10 \mathrm{~min}$. It also indicates here that any washing treatment can be made to this aggregate for $10 \mathrm{~min}$ can work properly.

- These aggregates are used without any type of treatment, i. e. without washing or any other treatment. Water absorption, specific gravity and density will further improve, if one can use these aggregates by proper treatment.

- Known source of RCA or unknown source of RCA has not major effect for Water absorption, specific gravity and density. Both types of aggregates are showing almost similar properties.

- Elongation and flakiness index were observed little higher for RCA. 
- All other properties of aggregates (i.e. aggregate crushing value, aggregate impact value, aggregate abrasion value etc) were showing values within IS limit for all source of recycled aggregates.

- Workability for fresh concrete was decreasing with increase of incorporation of recycled aggregates. There is also no effect for known or unknown source of aggregates.

\section{ACKNOWLEDGEMENT}

Research reported in this research was supported by Gujarat Council of Science and Technology (GujCOST), Department of Science and Technology; Govt of India. This support is greatly acknowledged.

\section{REFERENCES}

1. Sagoe-crentsil K. K., Brown T. and Taylor A. H. Performance of concrete made with commercially produced coarse recycled concrete aggregate. Cem Conc Res, 2001, 31(5), 707-12.

2. Meinhold U., Mellmann G. and Maultzsch M. Performance of high-grade concrete with full substitution of aggregates by recycled concrete. Proc of the 3rd CANMET/ACI Int Conf, USA, 2001, 85-96.

3. De Pauw P., Thomas P., Vyncke J. and Desmyter J; Shrinkage and creep of concrete with recycled materials as coarse aggregates. Proc of the Int Sym on Sustainable Const: Use of Recycled Concrete Aggregate. Thomas Telford, London, 1998, pp. 213-226.

4. Dhir R. K., Limbachiya M. C. and Leelawat T. Suitability of recycled concrete aggregate for use in BS 5328: Designated mixes. Proceedings of the Institution of Civil Engineers, Structures and Buildings, 1999, 134, No. 3, 257-274.

5. Akhtaruzzaman A A, Hasnat A. Properties of conc using crushed bricks as aggregate. Conc Int 1988;5(2):58-63.

6. IS: 12269 - 1987 Specifications for 53 - grade ordinary Portland cement.

7. IS: 3535 - 1986 Method of Sampling hydraulic cements - First Revision.

8. IS: 2 - 1960 Rules for Rounding Off Numerical Values (Revised)

9. IS: $650-1966$ Specification for standard sand for testing of cement (first revision)

10. IS: 4031 - 1996 (Part - 1) Method of Physical Tests for Hydraulic Cement - Determination of Fineness by Dry Sieving.

11. IS: 4031 - 1988 (Part - 3) Method of Physical Tests for Hydraulic Cement - Determination of Soundness.

12. IS: 4031 - 1988 (Part - 4) Methods of physical tests for hydraulic cement - Determination of consistency of standard cement paste (First Revision)

13. IS: 4031 - 1988 (Part-5) Methods of physical tests for hydraulic cement - Determination of Initial and Final Setting Times (First Revision)

14. IS: 4031 - 1988 (Part - 6) Method of Physical Tests for Hydraulic Cement - Determination of Compressive Strength of hydraulic cement other than masonry cement.

15. IS: 5513 - 1976 Specification for Vicat Apparatus.

16. IS: $5514-196$ Specification for apparatus used in Le-Chatelier test.

17. IS: 10080 - 1982 Specification for vibrating machine for casting standard cement mortar cubes.

18. IS: 10086 - 1982 Specification for moulds for use in tests of cement and concrete.

19. IS: 2430 - 1995 Methods for Sampling of Aggregates for Concrete.

20. IS: $460-1985$ (Part 1) Specifications for test of Sieves - Wire Cloth Test sieves (Third Revision)

21. IS: 460 - 1985 (Part 3) Specifications for test of Sieves - Methods of examinations of apertures of test sieves (third revision)

22. IS: 2386 - 1997 (PART I) Method of Test for Aggregate for Concrete - Particle Size and Shape.

23. IS: 2386 - 1997 (PART III) Method of Test for Aggregate for Concrete - Specific Gravity, Density, Voids, Absorption and Bulking.

24. IS: 2386 - 1997 (PART IV) Method of Test for Aggregate for Concrete - Mechanical Properties.

25. IS: $1199-1959$ Methods of Sampling and Analysis of Concrete. 